\title{
Memoria de la dictadura, hibridez y ambigüedad en $L a$ dimensión desconocida, de Nona Fernández
}

\author{
Memory, Hybrid Genres and Ambiguity in Nona Fernández's La \\ dimensión desconocida \\ Luna Carrasquer \\ Universidad de Utrecht \\ e.l.carrasquer@gmail.com
}

\begin{abstract}
Resumen: El presente artículo investiga la relación entre la hibridez genérica y la memoria de la dictadura en la novela La dimensión desconocida (2016) de Nona Fernández. El artículo argumenta que los géneros literarios de autoficción, docuficción y crónica facilitan la representación y la recuperación de la memoria individual y colectiva. El análisis narratológico demuestra que, alternando la ficción con los rasgos autobiográficos, documentales y cronísticos, se reconstruye la memoria individual fragmentada de la narradora, que completa sus recuerdos mediante la imaginación, y la memoria colectiva de la dictadura chilena, que se pretende ampliar y rescatar del olvido.
\end{abstract}

Palabras clave: narrativa chilena contemporánea, estudios de memoria, autoficción.

\begin{abstract}
This paper investigates the relation between hybrid genres and memory in Nona Fernandez' novel La dimensión desconocida (2016), which shifts between facts and fiction. Firstly, the hybrid genres of autofiction, docufiction and chronicle will be discussed, as well as the relation between literature and memory. Secondly, these concepts will be used in a narratological analysis of the novel to analyse how these genres affect the representation of individual and collective memory. This paper argues that the hybrid genres enable the representation and reconstruction of the narrator's incomplete individual memory and the collective memory of the Chilean dictatorship.
\end{abstract}

Keywords: contemporary Chilean narrative, memory studies, autofiction.

Recibido: $31 / 05 / 2020$

Aceptado: 16/10/2020 


\section{Introducción}

En 2017, la escritora chilena Nona Fernández (1971) recibió el Premio de Literatura Sor Juana Inés de la Cruz por La dimensión desconocida (2016). En su discurso, Fernández retomó unas palabras de Salvador Allende para animar a los jóvenes escritores a asumir la responsabilidad histórica. "Tenemos el privilegio del manejo de la pluma", dijo la escritora, "hagamos con él algo que dinamite, que nos explote en la cara y nos haga reaccionar. Ser escritor y no ser revolucionario, debiera ser también una contradicción hasta biológica". Esta responsabilidad histórica impregna su obra, en la que la memoria de la dictadura chilena está omnipresente. La obra narrativa de la escritora, que también es guionista y actriz, consta hasta el presente de seis novelas: Mapocho (2002), Av. 10 de julio Huamachuco (2007), Fuenzalida (2012), Space Invaders (2013), Chilean Electric (2015) y La dimensión desconocida (2016).

Patricia Paola Fernández Silanes, más conocida como Nona Fernández, pertenece a la generación de escritores chilenos nacidos en los años setenta, los llamados "hijos de la dictadura", término introducido para referirse a la generación que "experienced the dictatorship as children and collectively speak as second-generation survivors of Chile's national trauma" (Friedman 613). Al principio, según Friedman, las obras de estos escritores no se centraban en cuestiones políticas, sino en la cuestión familiar y la intimidad fracasada. Sin embargo, en algunas obras más recientes ha cambiado la actitud hacia el compromiso político, explorando "dictatorship's legacy within a broader social frame" (613-4). Friedman afirma, pues, que el nuevo deseo de esta generación es relacionar los temas privados con los temas políticos. Otra característica de la narrativa de esta generación de los hijos, es, en palabras de Ana Casas, la "ficcionalización de experiencia", con lo cual se borra la distinción clara entre "the fictionalized story and the writer's real life" (Franken Osorio 247). Franken Osorio aborda, además, un aspecto importante de la experiencia de Fernández y otros autores de su generación, como Alejandro Zambra: "as the author says, she and other recent writers are children of families where nobody was killed. They are children of the Pinochet education, and they have to speak of the scars, but without the wound" (247). La ausencia de muertos, según Bieke Willem, "permite mirar nostálgicamente hacia el pasado y hacia la infancia. Su nostalgia atípica no consiste sin embargo en una vuelta improductiva y paralizadora al pasado, sino en recordar e imaginar activamente este pasado", a la vez que implica "una mirada muy crítica al presente posdictatorial" (156).

Esto es evidente también en el caso de Fernández. Aunque no había muertos en su familia, toda su obra trata el tema de la dictadura chilena. Sus novelas son explícitamente políticas y trabajan el tema de la memoria: también La dimensión desconocida, cuya narradora pertenece a la generación de los hijos de la dictadura, como la autora. La narradora se centra en la historia del agente de la Fuerza Aérea An- 
drés Valenzuela — un torturador arrepentido que confesó sus crímenes a la prensa chilena durante la dictadura- e intenta reconstruir el pasado a partir de ese testimonio y de los recuerdos de su propia infancia. Así, la novela indaga, por un lado, en la memoria individual de la narradora y, por otro, en la memoria colectiva que ella explora para completar su propia memoria y para entender esta "dimensión desconocida" que es para ella la dictadura chilena. Para ello, se mezclan elementos (auto)biográficos e históricos con elementos ficcionales:

Mezcla de ficción, crónica y biografía, la novela traspasa las fronteras de los géneros, para formar parte de una tendencia cultural y artística a la producción de textualidades con pactos de lectura ambiguos. . . Son relatos que no se pretenden verídicos pero que, no obstante, llevan marcas de autenticidad, posibilitando modos diversos de vinculación entre memoria, identidad e historia. (Peller 64)

El presente artículo pretende analizar cómo la hibridez genérica sirve para reconstruir la memoria en La dimensión desconocida. En esta novela, la hibridez genérica se evidencia en la mezcla de recursos literarios propios de distintos géneros narrativos como la crónica, la autoficción y la docuficción, en los que se produce una tensión entre realidad y ficción. Parto de la hipótesis de que esta hibridez sirve para representar y completar los vacíos de la memoria individual y colectiva en la novela.

\section{La hibridez genérica en la narrativa de la memoria: autoficción, docuficción y crónica}

Astrid Erll afirma que tanto la literatura como la memoria colectiva producen versiones de la realidad y del pasado. Los géneros literarios son importantes para la cultura del recuerdo, porque sirven como modelos conocidos de representación, a través de los cuales se pueden elaborar las experiencias colectivas que son complejas de interpretar. Así "la creación literaria del mundo y la creación de sentido" que ofrece la literatura, se parecen a los procesos de la memoria colectiva, por lo cual se puede considerar la literatura como medio de la memoria (202). No obstante, se deben diferenciar los textos literarios de los medios escritos utilizados por otros sistemas simbólicos de la memoria colectiva, como la historiografía y los textos legales, por ejemplo (202). La ficción permite superar límites, ya que "elementos de los ámbitos extraliterarios de lo real y lo imaginario se vuelven irreales, o bien reales en el medio de la ficción" (203). Esto se evidencia en la docuficción, una modalidad narrativa a la que me referiré más adelante, en la que con frecuencia se integran fuentes históricas como testimonios o fotos en un texto ficcional. Además, las obras literarias permiten que se manifieste la variedad discursiva de una 
cultura del recuerdo, visto que representan diferentes formas de hablar y diferentes discursos (204). Así pues, los géneros híbridos en los que se produce una tensión entre realidad y ficción tienen un protagonismo especial en la narrativa de la memoria, donde se recurre a ellos "para crear un efecto de veracidad" (Lauge Hansen 24). Los narradores expresan a menudo en su discurso qué partes proceden de una fuente o de un testigo y cuáles han imaginado, generando una sensación de autenticidad. La inseguridad sobre lo narrado y la problemática de la fidelidad a los hechos se expresa a veces "a través del uso explícito de la imaginación de forma autorreferencial" (32). Según Lauge Hansen, este tipo de recursos revelan "la búsqueda de una forma estética adecuada para representar esta posible verdad de forma artística" (32).

La ambigüedad entre lo referencial y lo ficcional forma la base de la noción de autoficción. La autoficción comprende "textos de muy diversa índole, que tienen en común la presencia del autor proyectado ficcionalmente en la obra. . . así como la conjunción de elementos factuales y ficcionales, refrendados por el paratexto" (Casas 11). Para Casas, la ambigüedad es inherente al concepto de autoficción, dado que "el desorden cronológico, la estructura caótica, habitualmente digresiva de la autoficción, cuestionan. . . las nociones de sucesión y significación que en la autobiografía tienden a ofrecer una imagen de síntesis tanto de lo acontecido como del propio yo" (39-40). Alberca destaca como rasgo principal de la autoficción la relación ambigua que tiene este concepto con el pacto novelesco o de ficción y el pacto autobiográfico (159). El pacto autobiográfico implica una suerte de contrato entre el autor y el lector, según el cual las figuras del autor, narrador y protagonista de la obra se identifican como la misma persona (67), al tiempo que el autor hace una promesa de veracidad, que implica que lo narrado puede ser "comprobable a veces por el lector, que espera o exige el máximo de correspondencia entre el texto y la realidad nombrada por éste" (69). En el pacto novelesco, por el contrario, la promesa de veracidad no tiene importancia. Este pacto se caracteriza por el distanciamiento entre autor y narrador, por lo cual el enfoque está en el narrador y la historia que narra (70-1). Así pues, el narrador cuenta la historia como si fuera verdadera y el lector acepta la ficción, y esta no se identifica con el mundo real —aunque el mundo imaginario de la ficción bien puede relacionarse con el mundo real- (73). La autoficción se situaría entre estos dos pactos de lectura. En la autoficción coinciden los nombres de autor, narrador y personaje, lo cual crea, según Alberca, inestabilidad y confusión en la expectativa del lector: la invitación a una interpretación autobiográfica queda en entredicho por la introducción de elementos ficcionales en el texto (128-9).

También la docuficción, como ya indica el término, es un género híbrido en el que se mezclan elementos, técnicas y estrategias documentales y ficcionales (Von 
Tschilschke y Schmelzer 16). Hay varias maneras en las que se puede aplicar la docuficción; a saber, como un acercamiento de un documento a una ficción, o de una ficción a un documento. La primera opción tiene que ver con la introducción de elementos ficticios; a través de la creación "de sentido que resulta de la elaboración de una trama que relaciona los elementos documentales" o a través de "la adopción de códigos y estrategias representativas connotadas con la ficción" (estructuras narrativas, por ejemplo) (16). La segunda opción se realiza a través de la referencia a documentos como fuentes históricas; a través de la integración de materiales documentales (textos o imágenes) o a través del "recurso a formas y estrategias representativas convencionalmente interpretadas como documentales", como la carta o el diario (16). En todo caso, la docuficción "se mueve en la escala entre el degré zéro de una pura anotación de 'hechos' y una ficción que renuncia a toda autentificación" (16).

A pesar de que algunos críticos consideran que los textos cronísticos son meramente informativos, según Yanes Mesa tienen "algo más que pura información, ya que su identidad está determinada por la interpretación y valoración de lo narrado" (s.p.). En general, el orden cronológico y la mención de datos exactos como fechas y horas, constituyen los rasgos principales de la crónica, en la que se utiliza, además, un lenguaje común. Además, destaca el estilo creativo y literario del género. En su estudio sobre la crónica chilena contemporánea, Poblete Alday se refiere a una "creciente inclusión de las narrativas del Yo" que resulta en la conjugación de "espacios y estrategias de enunciación; modalidades textuales canónicas y productos de la cultura de masas; subjetividades múltiples. . . y, sobre todo, la activación conjunta de horizontes de expectativas provenientes de distintos registros textuales" (1167). Con todo ello, se mezclan lo público y lo privado, "en cuyo vaivén se va constituyendo lo íntimo, que por lo mismo, ya no equivale - como en la época de la crónica modernista - a lo verdadero, ni tampoco a lo auténtico" (1167). Se confirma así la hibridación de un género literario que se puede considerar un género híbrido en sí: "la llamada posmodernidad parece abonar —en la más amplia acepción del término - la hibridez constitutiva de la crónica" (1170).

Se evidencia, pues, que tanto la crónica, como la docuficción y la autoficción juegan de una u otra manera con la realidad y la ficción. Cada uno de los géneros literarios descritos es en cierta medida un género híbrido que juega con la alternancia de elementos factuales y ficcionales, que influyen en la representación de la memoria en la literatura. A continuación, se analiza la manera en que estos géneros literarios híbridos se utilizan para reconstruir y completar los huecos de la memoria individual y colectiva en La dimensión desconocida. 


\section{Entre la autenticidad y la ambigüedad: rasgos auto- y docuficcionales en La dimensión desconocida}

La dimensión desconocida parte del testimonio que dio el agente de la Fuerza Aérea Andrés Valenzuela Morales a la revista Cauce en 1984. La narradora de la novela recuerda haber leído este testimonio, con el título "Yo torturé" en la portada, y recuerda también la foto del torturador arrepentido. Años después, trabajando en el guion de un documental sobre la labor de la Vicaría de la Solidaridad, la narradora se ve confrontada de nuevo con Valenzuela, cuando ve y escucha su testimonio en la pantalla. Fascinada por su historia, la narradora, cuyo apellido es Fernández, relata las historias de las víctimas que él menciona en su testimonio, entrelazándolas con sus propios recuerdos de la infancia y otros acontecimientos de la historia chilena de esa época. La serie estadounidense de los años sesenta The Twilight Zone, introducida en Latinoamérica como La dimensión desconocida, presta su nombre al título de la novela. Algunos episodios de esta serie, que la narradora veía siempre de niña, sirven como herramienta literaria, como eslabón, para narrar las historias de las víctimas de la dictadura. ${ }^{1}$

¿Cómo se imbrican los recursos auto- y docuficcionales en la novela? Antes de analizar la novela en sí, conviene indagar en su paratexto. La contraportada alude ya al caso de Valenzuela como disparador del relato. Es un hecho verificable que el testimonio de Valenzuela es real y que fue publicado en la revista Cance, tal como se describe en la novela. ${ }^{2}$ Esto se confirma también en la contraportada, que describe que "siguiendo la hebra de esta escena real, Nona Fernández activa los mecanismos de la imaginación para acceder a rincones donde la memoria y los archivos no han podido llegar". Aparte de señalar que la novela parte de una historia real, la contraportada también indica que la imaginación juega un papel importante. Se puede deducir, pues, de esta contraportada, que la caracterización genérica es novela.

A pesar de que la contraportada no anuncia que haya una correspondencia entre la figura de la narradora y la autora, se pueden encontrar varias pistas autobiográficas en la novela que permiten observar la proyección de la figura de la autora en la de la narradora. Tanto la autora, Nona Fernández, como la narradora, son guionistas de un documental sobre la Vicaría de la Solidaridad. En La dimensión desconocida no se menciona el título del documental, que en el mundo extraliterario se correspondería con Habeas Corpus (2015), dirigido por Claudia Barril y Sebastián

1 Fernández recurre frecuentemente a la cultura popular en su obra novelística para tratar de la dictadura chilena. En Space Invaders (2013), por ejemplo, recurre al videojuego homónimo de los años ochenta.

2 La periodista que entrevistó a Valenzuela en 1984, Mónica González, publicó también un libro que incluye su entrevista con el ex agente de la FACH, llamado Apuntes de una época feroz (2015). 
Moreno con guion de Nona Fernández. Asimismo, Nona Fernández y la narradora fueron compañeras de clase de Estrella González, cuya historia ya se cuenta en Space Invaders (2013) y es retomada en La dimensión desconocida. Es justamente en este fragmento intratextual, incluido en el capítulo final de la novela, que la narradora se identifica a sí misma por primera vez, revelando su apellido: "Elgueta, presente. Fernández, presente. Y ella siempre después de mí en el listado. González, presente" (179). La narradora vive con su pareja "M" y su hijo "D" y los únicos otros familiares a los que alude son su madre y su abuela, sin mencionar sus nombres. Todo esto se corresponde, de nuevo, con los datos biográficos de la autora empírica, que es hija de madre soltera y que actualmente vive con el director teatral Marcelo Leonart con quien tiene un hijo, Dante (Selicki Acevedo s.p.). Las iniciales aparecen también en la dedicatoria de la novela: "Para M, D y P, mis letras fundamentales".

De estas coincidencias se podría concluir, pues, que la narradora de La dimensión desconocida coincide con la autora empírica. Aunque los datos que ofrece no sean muy completos y la identificación no sea explícita (solamente menciona las iniciales, no menciona el título del documental y su apellido aparece tan solo al final), la novela permite una lectura autoficcional. Además, tanto la narradora como la autora pertenecen a lo que la crítica ha llamado la generación de los hijos de la dictadura. No obstante, como ya se ha señalado en el marco teórico, la autoficción va más allá que la fusión formal de elementos autobiográficos y elementos ficcionales. Un aspecto clave de este concepto es la ambigüedad, que complica la clara distinción de realidad y ficción para el lector. La autoficción simula y engaña, aprovechando el pacto novelesco y autobiográfico a la vez. En el caso de La dimensión desconocida, se puede afirmar que se cumple con el requisito formal de mezclar elementos autobiográficos y ficcionales.

Sin embargo, la pregunta es en qué medida se puede hablar de incertidumbre, confusión y ambigüedad en la novela, ya que llama la atención que en La dimensión desconocida se explicita cuándo se utiliza la imaginación, es decir, la ficción, y cuándo se trata de un acontecimiento real —una técnica recurrente en la narrativa de la memoria, como comentaba Lauge Hansen (32). Uno de los fragmentos en los que se evidencia esto es el siguiente:

Lo imagino otra vez caminando por una calle del centro. Es el hombre alto, delgado, de pelo negro, con sus bigotes gruesos y oscuros. Creo que viste la misma ropa con la que lo vi en esa fotografía vieja de la revista Cauce, una camisa cuadrillé y una chaqueta de mezclilla. Esta vez no lo imagino fumando. Lleva las manos en los bolsillos, quizá capeando el frío de esta tarde de agosto de 1984. Lo imagino observando cada rostro que se cruza delante 
de sus ojos. Mira ansioso intentando adivinar cuál de todos es su siguiente contacto. $^{3}(59)$

En este fragmento, la narradora enfatiza en cada frase que está imaginando la escena, aunque se trate de un día específico, el día en que Valenzuela dio su testimonio a la periodista. A pesar de esto, se nota el registro novelístico en las descripciones: la narradora explica que lleva las manos en los bolsillos y que mira ansioso, presentando estos detalles como verosímiles: efectivamente, pudo ser así. Sin embargo, se recuerda al lector en cada frase que la escena que está leyendo es parte del ejercicio de la imaginación de la narradora, un recurso frecuente en la narrativa de la memoria, tal y como señalaba Lauge Hansen (32). La novela está impregnada de fragmentos así, en los que palabras como "lo imagino", "probablemente" o "quizá" son repeticiones frecuentes.

No obstante, existen también claras indicaciones en la novela respecto a lo factual. Por ejemplo, se repite varias veces la información en la tarjeta de identificación de Valenzuela, que dice "Andrés Valenzuela Morales, soldado 1", carnet de identidad 39.432 de la comuna de La Ligua" (16). Aparece por primera vez cuando la narradora menciona, además, que hay una fotografía en el centro "con el número de registro 66.650, que no imagino, que leo aquí, en el testimonio que la misma periodista escribió tiempo después" (16). Más adelante, la narradora se refiere de nuevo al carnet de identidad, cuando lo ve "en una fotocopia que el mismo abogado me pasó años después cuando hablamos de este momento” (116). Se enfatiza, pues, que no se trata aquí de un aspecto imaginado, sino de un documento real que se puede verificar. Por tanto, se puede decir que se trata aquí de una forma de docuficción, dado que los datos del carnet de identidad están integrados en el texto. Llama la atención que se repiten estos datos a lo largo de la novela, lo que podría ser explicado quizá por la necesidad de enfatizar la credibilidad y la legitimidad de los hechos narrados.

De todas formas, hay también algunas partes en la novela en las que no se le comunica al lector si lo narrado es parte del ejercicio de imaginación o responde a documentos o testimonios reales. Es aquí donde verdad y ficción se mezclan sutilmente, como ocurre en el siguiente fragmento:

Diez años después de esta detención en la que no participó, el hombre que torturaba se encuentra en un salón parroquial. . . La luz de una ampolleta los ilumina. Hay un par de tazas de té o café humeando sobre la mesa, servidas hace poco por alguna monja discreta que no pregunta ni observa de más. Hay

3 La negrita es mía. 
también un cenicero con algunas colillas apagadas develando que ha transcurrido tiempo desde que llegaron. Los imagino sentados. (79)

Tan solo al final del fragmento citado vuelve a aparecer otra vez la indicación "los imagino", pero la parte que la precede es descriptiva y novelística. Se narra la escena sin indicar claramente si se trata o no de un ejercicio de imaginación. En este caso sí se genera, en palabras de Alberca, un "aura de incertidumbre". En la mayoría de los fragmentos, sin embargo, la narradora indica si está recordando o imaginando una escena.

A continuación, cabe destacar una serie de fragmentos de la novela cuya existencia extraliteraria no es posible verificar y que pueden considerarse como un ejemplo de docuficción: la correspondencia entre la narradora y Andrés Valenzuela, que consiste principalmente en los fragmentos resaltados en cursiva en la novela. En el primer capítulo, la narradora expresa su deseo de contactar con Valenzuela, de transmitirle un mensaje, porque "no sabe que estoy aquí con intenciones de hablarle" (25). Se imagina cómo se pondría en contacto con él, usando el condicional: "en ella [la carta] le contaría que quiero escribir sobre él y que me parece justo informárselo y quizá, si se anima, hacerlo parte de este proyecto que imagino" (25). A continuación, la narradora redacta una carta para Valenzuela. El primer fragmento en cursiva se encuentra en la página 56 y está escrito en primera persona. En primer lugar, parece ser parte del testimonio o diario íntimo de Valenzuela que narra sus experiencias y sentimientos. Los fragmentos en cursiva que siguen son iguales, pero más adelante se refiere a la carta de la narradora:

Si, a veces sueño con ratas.

Con piezas oscuras y con ratas.

Con mujeres y hombres que gritan, y con cartas como la suya, que llegan desde el futuro preguntando por esos gritos.

No sé qué responderle.

Ya no entiendo lo que dicen esos gritos.

Tampoco lo que dicen las cartas. (129)

Se implica aquí la existencia de una correspondencia entre la narradora y Valenzuela. Más adelante, a través de la voz de Valenzuela se alude no solamente a la carta de la narradora, sino al texto en general, como un comentario metaficcional: "usted lo ha contado mejor que yo. Su imaginación es más clara que mi memoria" (160). Además, al final de la novela, se puede leer:

No sé cómo hizo usted para escribirme.

No sé cómo hizo usted para que su carta terminara llegándome. 


\author{
¿Para qué quiere hacer un libro sobre mi? \\ $\ldots$ \\ Me encontrarán aquí o donde sea, \\ y alguno estará dispuesto \\ a manchar sus pantalones con mi sangre. \\ Quizá sea usted misma. \\ Quizá ya lo bizo abi en el futuro. \\ Nada es bastante real para un fantasma. \\ ¿Qué más puedo decirle? \\ Recojo callampas en el bosque, leo por las tardes. \\ $Y$ en las noches sueño con ratas. (175-6)
}

Este es el último fragmento de la novela en cursiva, las últimas palabras desde la voz narrativa de Valenzuela. Más adelante, al final de la novela, contesta de nuevo la narradora en forma de carta. Empieza con las palabras "Estimado Andrés" e incluso cierra con un lugar y una fecha, conforme a las convenciones de las cartas: "Papudo, V Región, junio 2016" (233).

Dado el lenguaje literario que se utiliza en estos fragmentos es muy probable que no se trate aquí de una correspondencia real, sino ficcional. Aun así, es interesante destacarlos como recurso docuficcional: se incorpora un recurso documental con los mecanismos propios de la ficción. La letra en cursiva y el estilo testimonial distinguen estos fragmentos del resto de la novela. Dado que se permite la interpretación de una correspondencia, el personaje de Valenzuela se vuelve más vivo, se le otorga una voz en vez de simplemente hablar de él como el represor o torturador. Como señala la autora en una entrevista, se trata de "alguien convertido en un monstruo pero que conservó siempre un rastro de humanidad" (Rodríguez Marcos s.p.).

Más credibilidad tienen los fragmentos en los que la narradora pretende citar algunas frases que pronunció Valenzuela en la entrevista con sus amigos-directores. La grabación está, según cuenta, entre los materiales que ella tiene que analizar para el guion, y reproduce algunas frases de Valenzuela que le llaman la atención. Como las supuestas cartas, estas frases están escritas en cursiva (24). Más adelante, en la página 156, se encuentra otro fragmento del testimonio de Valenzuela, otra vez en cursiva, pero esta vez sin anunciarlo. Aparece, supuestamente, en otra grabación que la narradora está viendo. De nuevo, se trata aquí de un acercamiento de la ficción a, en este caso, un testimonio que se presenta como verídico, aunque no se pueda comprobar esto en la novela. Con estos recursos autoficcionales y docuficcionales se fusionan elementos reales y ficticios, cuya tensión se sintetiza quizá de mejor manera en esta reseña de la novela: "Por más que se intenta un registro fidedigno, hay por cierto una 'novelización' de los eventos narrados, pero el 
recurso, en vez de trivializarlos, tiene el efecto de volverlos dramáticamente reales" (Torche s.p.). Además, los dos recursos, como representantes de la fusión genérica y la incertidumbre, representan la memoria individual de la narradora.

\section{Recuperación de la memoria: historias que se entrelazan y la construcción de dimensiones}

La narradora-autora de La dimensión desconocida vivió la dictadura de Pinochet de niña. Por tanto, su memoria de esta época es fragmentada y confusa, lo cual genera una fascinación obsesiva con el pasado: "no comprendía, ni aún comprendo, todo lo que pasó a mi alrededor cuando era niña y supongo que intentando entender un poco quedé hechizada por sus palabras, por la posibilidad de descifrar con ellas el enigma" (26). Siendo "hija de la dictadura", le cuesta imaginar lo que pasó exactamente en esta época. Esto se enfatiza frecuentemente en la novela, señalando que carece "de palabras y de imágenes para escribir lo que sigue de este relato" y que "cualquier intento que haga será pobre al querer dar cuenta de ese íntimo momento final de alguien a punto de desaparecer" (35). Los fragmentos de este tipo van acompañados a menudo por múltiples preguntas y dudas de la narradora, preguntándose qué vieron y pensaron las víctimas y qué les hicieron.

Es evidente que en la trama de la novela se vincula repetidamente cada historia del pasado con el ejercicio de la imaginación del presente. Como indica la narradora-autora antes de relatar la detención de los hermanos Flores, por ejemplo, la historia "es tan similar a las que ya he imaginado que en este punto todo se mezcla y se confunde en una plantilla de acción predecible y hasta aburrida" (78). Además, como ya se ha señalado en este análisis, la narradora indica frecuentemente qué momentos imagina y cuáles no. En esto se evidencia, pues, una conciencia de la construcción narrativa. Hay otros fragmentos metaficcionales en la novela en los que se enfatiza esta conciencia de la narradora-autora, que indica ya en el primer capítulo de la novela: "a partir de ese momento ya no sé más. Todo es un ejercicio imaginativo" (44). Además, se enfatiza que ella decide qué lee el lector y cómo lo interpreta:

si el lector hubiera puesto real atención a los datos objetivos planteados en todo este libro, habría asumido la presencia de M. . . El truco ha sido no enfocar la atención en M. Hasta ahora, que doy la instrucción para dejar de mirar la esquina superior izquierda y ver la pantalla completa. (132-3)

Fernández se refiere aquí a un especial de la serie de televisión, Juegos de la mente, que se trata de los montajes comunicacionales de la dictadura que desinformaban y mentían. Como en la serie y como en el discurso unilateral de la dictadura, la narradora tiene el poder de decidir qué acontecimientos lee el lector y cuáles no. Lo hace 
conscientemente y demuestra así la construcción arbitraria de la narración, que es, como la memoria colectiva, una selección de fragmentos. Más adelante, reflexiona aún más sobre la construcción narrativa:

Aquí debiera hacer un nexo con el hombre que torturaba. Seguir la regla que yo misma he establecido y develar el extraño y torcido vínculo que existe entre él y González, eslabones lejanos o cercanos de una larga y pesada cadena. . . Pero no lo haré. Enfocaré otras áreas de la pantalla. (182)

Se revela aquí la estrategia que utiliza la narradora-autora de vincular constantemente sus recuerdos infantiles con historias reales. "Así se cierra esta historia, sin ninguna mención al hombre que torturaba y con la imagen de Estrella González Jepsen derribada por manos de un carabinero" (193).

Ahora bien, la imaginación de Fernández, que crea los elementos ficcionales de la novela, permite la construcción de la dimensión desconocida. La dimensión desconocida representa, claro está, la realidad horrorosa de la dictadura a la vez que la memoria fragmentada o incompleta de Fernández, quien no conoce bien esta "realidad paralela, infinita y oscura" (19). En la novela, se alude a la dimensión desconocida como si fuera un espacio concreto en el que se puede estar y moverse: "volví a entrar a esa dimensión oscura, pero esta vez con un farol que había cargado durante años y que me permitía moverme mucho mejor ahí dentro" (21). También se presenta la dimensión desconocida como un hoyo negro o "espacio exterior en el que naufragan perdidos", que traga a todos estos que acceden a él (47).

La línea entre este espacio o mundo y la vida cotidiana es frágil, y los dos mundos se funden en la novela. Así, el testimonio de Andrés Valenzuela, el "mensajero del lado oscuro, conocedor de esa dimensión secreta", sirve como hilo conector entre las historias, entre el pasado y presente que se entrelazan continuamente (34). Se vinculan las historias del pasado (de Valenzuela y de las víctimas) a los recuerdos de infancia o la vida cotidiana de la narradora. Así, se establecen muchas comparaciones entre las diferentes historias que se opta por narrar en la novela. La primera historia de las víctimas es la de José Weibel y su familia. Para narrar la detención de José Weibel, se usa el eslabón de la rutina mañanera. Tras describir la rutina de su propia familia, Fernández da un giro al pasado:

Desconozco cómo habrá sido la rutina mañanera en la casa de los Weibel Barahona en 1976. Yo apenas tenía cuatro años, no recuerdo ni cómo eran mis propias mañanas en ese tiempo, pero con un poco de imaginación puedo ver esa casa ahí en La Florida y a esa familia comenzando la jornada. (30) 
A partir de ahí, pues, arranca Fernández el ejercicio de la imaginación e intenta vincular el pasado desconocido con lo que sí sabe, su propia vida: "no creo que su rutina se haya diferenciado mucho de la que día a día yo misma ejecuto con mi familia" (30). Así, se entrelazan estas dos dimensiones, a veces incluso en una misma frase: "El 29 de marzo de 1976 a las 07:30 horas, la misma hora en la que mi hijo y su padre se van a diario de nuestra casa, José y María Teresa salieron con sus niños para llevarlos al colegio" (30). Otro vínculo que establece Fernández en esta escena es el de la instantánea mental de la familia, que ella misma hace de su hijo y su pareja en el momento en el que se van. A continuación, se pregunta si José también habrá hecho una instantánea mental de su familia cuando los agentes lo detienen. Como en las otras historias que trata la novela, José Weibel es llevado a la dimensión desconocida y desaparece de la vida cotidiana. Al final, cuando le fusilan, "el hechizo protector se rompe, su cuerpo se va por el río y desaparece para siempre" (36).

Tal forma de vincular y entrelazar las historias se aplica de una u otra manera a cada historia de las víctimas que se narra en la novela. En el caso de la detención de Carlos Contreras Maluje, Fernández vincula el testimonio de su madre al testimonio de Valenzuela. Recuerda que su madre le contó, a su abuela y a ella, la detención de un hombre que se había lanzado a las ruedas de una micro. Ese hombre fue Contreras Maluje y Valenzuela estaba ahí: "mi madre no lo sabe, pero esa mañana estuvo junto al hombre que torturaba. Parte de este relato confuso que ella hizo y sigue haciendo a mi pedido es un trozo de lo que él declaró a la periodista en su testimonio" (50). A continuación, Fernández narra la versión de Valenzuela y enfatiza que los dos mundos se fusionaron en este momento, antes de que Contreras Maluje desapareciera "definitivamente de los límites de la realidad" (50). Su madre y las otras personas que estuvieron en ese momento, "todos los que habitaban el mundo aparente de la vida cotidiana y normal fueron testigos por un momento de esa grieta por la que se asomaba la dimensión desconocida" (51). Fernández se imagina que mientras ellas almorzaban, Contreras Maluje soportaba combos y patadas en la calle Dieciocho, un centro de detención muy cerca de su vieja casa.

Además de relacionar aquí su vida cotidiana en ese día del pasado con lo que ocurrió simultáneamente en la dimensión paralela que desconocía y aún desconoce, establece otro vínculo entre Contreras Maluje y el coronel Cook, un personaje de la serie La dimensión desconocida. En ese episodio, el coronel, un viajero del espacio, se queda solo en un pequeño planeta desconocido en el espacio porque su nave ya no funciona. Desde este planeta envía mensajes a la tierra para que alguien vaya a su rescate y, en este punto, vincula Fernández al viajero del espacio con Contreras Maluje, quien fue llevado de los límites de la realidad: "probablemente mientras nos servíamos jalea y la bañábamos de leche condensada, como tanto nos 
gustaba hacer para el postre, Carlos Contreras Maluje enviaba mensajes mentales a los suyos para que alguien fuera a rescatarlo a ese planeta pequeño y solitario en el que había caído" (51). Así se mezclan el episodio de la serie, la vida cotidiana de la narradora-autora y la historia de la víctima basada en el testimonio de Valenzuela. Como demuestran estos ejemplos, se contrapone en La dimensión desconocida la cotidianeidad con la acción del terror. La dimensión desconocida es "esa zona de grises donde el horror convive con la vida diaria” (Rodríguez Marcos s.p.). Las historias cotidianas y las de la serie refuerzan así lo siniestro y facilitan, además, el vínculo entre lo íntimo y lo público. La ficción se convierte, pues, en una necesidad para completar la memoria individual fragmentada de Fernández, que pertenece a la generación de los setenta, "ese tiempo enrarecido en el que nos tocó crecer" (Fernández 197).

\section{Los elementos cronísticos como medio para el rescate del olvido}

A pesar del uso de los mecanismos propios de la ficción y la imaginación en La dimensión desconocida, la novela parte de hechos reales y busca rescatar del olvido a las víctimas reales cuyas historias relata. Con el estilo cronístico se añade una capa más de hibridación a la novela, se recupera la memoria colectiva y se iluminan las partes de esta que fueron ignoradas por el discurso hegemónico. La crítica a la memoria institucionalizada es evidente en la novela y se expresa tanto explícita como implícitamente. Cabe destacar aquí los fragmentos en los que la narradora-autora visita el Museo de la Memoria y los Derechos Humanos de Chile, que fue inaugurado en enero de 2010. Durante la inauguración, según narra Fernández, estaban presentes los presidentes de la Concertación, "que estuvo a cargo de lo que los analistas políticos llaman la Transición chilena, ese período en el que el discurso oficial fue la reconciliación y la justicia en la medida de lo posible" (37). El discurso de la presidenta Michelle Bachelet, que inaugura la "versión legitimada de nuestra memoria reciente", fue interrumpido por dos mujeres que reclamaban justicia por los muertos y presos políticos chilenos. A continuación, entre dos líneas en blanco que interrumpen la narración de los acontecimientos en el museo, Fernández se pregunta “¿cómo se hace la curatoría de un museo sobre la memoria? ¿Quién elige lo que debe ir? ¿Quién decide lo que queda afuera?” (38). No ofrece respuestas, simplemente cuestiona y continúa su narración sobre la inauguración.4

Además, en las mismas páginas que narran la visita al Museo de la Memoria, se evidencia que la novela busca darle un lugar en la historia a Valenzuela, que ahora brilla por su ausencia: "Su figura no es parte del bien o del mal, del blanco o del

4 Tal como afirma Nona Fernández en una entrevista: "en mis novelas trato de elaborar un lugar de reflexión, de entrega de respuestas también y de entrega de inquietudes más que respuestas, porque claro, no voy a ser yo la que dé las repuestas, sin duda, pero sí el lugar de la inquietud" (Sepúlveda 253-4). 
negro. El hombre que imagino habita un lugar más confuso, más incómodo y difícil de clasificar, y quizá por eso no encuentra espacio entre estas paredes" (42). Valenzuela se encuentra en un espacio gris, en un matiz de la historia chilena y la memoria colectiva, en la que no hay lugar para ninguna "Zona de Torturadores que se dan la Vuelta" ni para la "Zona de los Arrepentidos" (52). Cuando la narradora-autora le busca en la pantalla táctil que sirve para buscar información sobre las víctimas cuyas fotos están colgadas en una pared del museo, de nuevo sabe que no lo encontrará: "un hoyo negro lo consumió igual que al resto, y si quiero encontrarlo la única posibilidad es aquí, frente a esta pantalla que es como una torre de control, una radio con señal a ese planeta inquietante, única zona que no tiene cabida en este museo" (52). La dimensión desconocida y oscura no simboliza solamente el horror de la dictadura, sino también la desaparición y el olvido.

Como ya se ha mencionado, el género literario de la crónica se caracteriza principalmente por el estricto orden cronológico y las descripciones detalladas. Hay dos fragmentos en la novela en los que se evidencian estos rasgos cronísticos. En la historia sobre el niño Mario, la escena de la detención está descrita detalladamente, con los minutos exactos:

A las 16.30 horas se desarrolla la primera jugada importante de la tarde: Alejandro, alias Raúl, el padre no padre de Mario, se despide de él con un beso en la frente y sale de la casa. Volverá luego, dice. A las 16.35 horas, Hugo, alias el tío José, se instala junto a Mario en el living y le conversa sobre sus años de estudiante en su país de origen, Argentina. . . A las 18.00 horas, ... A las 19.50 horas, ... A las 19.55 horas (151-2)

Así continúa la descripción hasta las 20:59 horas, describiendo casi minuto a minuto lo que ocurre. En la historia de José Weibel, como ya se ha mencionado, también se encuentran claras indicaciones del tiempo exacto en el que ocurren los acontecimientos. La narradora utiliza las mismas horas de su propia mañana para recrear la rutina mañanera de los Weibel. Esto facilita la imaginación, y, por tanto, la reconstrucción detallada de la historia para ella, ya que la vincula con su propia vida. La crónica sirve, entonces, para recuperar detalladamente la memoria.

Otro ejemplo de un fragmento cronístico es la enumeración de acontecimientos al final de la novela. Aunque no se mencione aquí exactamente el momento, los acontecimientos están en orden cronológico. Durante catorce páginas se enumeran, en orden cronológico, los acontecimientos históricos en Chile y el mundo a partir del Golpe Militar, los recuerdos personales de Fernández y las historias de Valenzuela y las víctimas: 
Secuestran a Contreras Maluje a cuadras de mi casa, mi mamá ve la detención y luego nos la cuenta a la hora de almuerzo.

El Quila Leo es asesinado.

El hombre que torturaba

llora a escondidas en su cuartel.

Se disuelve la DINA y se crea la CNI,

Central Nacional de Informaciones (213-4)

Las frases son cortas y el lenguaje nada rebuscado, como si fueran titulares de prensa. De esta manera, se entrelazan, de manera sencilla, la memoria colectiva y la memoria individual, aunando nuevamente lo público y lo íntimo.

Así, pues, La dimensión desconocida busca rescatar, cuestionar y matizar. Utilizando los diferentes recursos genéricos que cruzan los límites de lo referencial y lo ficcional, Fernández intenta completar la memoria individual y recuperar la memoria colectiva de la dictadura chilena, visualizando "los detalles no mencionados" sin hacer caso "a las instrucciones que me dieron" y mirando "todas las esquinas de la pantalla” (141).

\section{Conclusiones}

A través de la hibridez genérica — más en concreto, la (auto y docu)ficción y la crónica- y la tensión entre realidad y ficción que esta implica, se representan y se completan los vacíos de la memoria individual y colectiva en La dimensión desconocida. Se ha evidenciado en el análisis que la reconstrucción (meta)ficticia por parte de la narradora-autora juega un papel importante. La imaginación y la ficción sirven en la novela para completar la memoria individual fragmentada de la narradora, quien intenta reconstruir acontecimientos que ocurrían en su infancia y que nunca había llegado a entender completamente. Además, la novela contribuye a dar a conocer hechos e historias: representa y recupera también la memoria colectiva, tanto las historias de las víctimas, que sí se encuentran en la versión legitimada de la memoria, como la de Valenzuela, que está en una zona gris entre el bien y el mal. Asimismo, la construcción ficticia de la novela mezcla la intimidad familiar de la narradora con la intimidad de las víctimas. Así, se crea un contraste que refuerza la presencia de lo siniestro en los tiempos de la dictadura, alternando las historias de la vida cotidiana con las que ocurren en la dimensión desconocida.

También se ha evidenciado que la novela parte de una historia real, de un documento real, de hecho, que es el testimonio de Valenzuela que leyó la narradora-autora cuando estudiaba en el liceo. La mezcla de ficción y realidad, característica por excelencia de la docuficción y la autoficción, crea, por un lado, un aura de veraci- 
dad en el texto. Por otro lado, estas formas literarias híbridas establecen un aura de cierta incertidumbre y ambigüedad, que representa precisamente la memoria individual de la narradora-autora, cuya memoria está fragmentada porque durante el período era tan solo una niña. A través de la autoficción se recupera, pues, parte de la memoria de una generación, la de los hijos de la dictadura, lo que es reforzado y justificado por el rasgo autobiográfico, es decir, la identificación entre la narradora y la autora empírica. El uso de la docuficción también contribuye a forjar esta aura ambigua y facilita la representación y la recuperación de la memoria colectiva en el sentido de que, como se ha comentado, le otorga una voz a Valenzuela en la supuesta correspondencia entre éste y la narradora-autora.

Por último, se han analizado los rasgos cronísticos de La dimensión desconocida, que se revelan en el orden cronológico, la precisión del tiempo y, en general, el carácter descriptivo y detallado de algunas escenas comentadas. Además de recuperar la memoria colectiva en la historia del niño Mario a través de una reconstrucción muy precisa y detallada, los rasgos cronísticos facilitan, en la escena de los Weibel, que la narradora-autora complete la memoria al vincular la historia de los Weibel con su propia vida. La enumeración cronológica al final de la novela facilita, además, la representación estructurada y resumida de la mezcla de la memoria individual y colectiva.

Así, cada género literario que el presente artículo ha tratado sirve para representar y completar los vacíos de la memoria en La dimensión desconocida. Alternando ficción con historia, la novela reconstruye las historias del perpetrador arrepentido y las víctimas para rescatarlas del olvido y para reforzar la memoria colectiva. Para esto, se sirve de la imaginación y de los recursos propios de la ficción, porque su propia memoria fragmentada y el documento no alcanzan para penetrar en esa "dimensión desconocida". De esta manera, Fernández vuelve a tomar la responsabilidad histórica en La dimensión desconocida. Como decía la propia autora, "la memoria es un motor de vida y de reflexión inagotable". 


\section{Obras citadas}

Alberca, Manuel. El pacto ambiguo. De la novela autobiográfica a la autoficción. Madrid: Biblioteca Nueva, 2007.

Casas, Ana. "El simulacro del yo: la autoficción en la narrativa actual." La autoficción: reflexiones teóricas. Comp. Ana Casas. Madrid: Arco/Libros, 2012. 9-42.

Erll, Astrid. Memoria colectiva y culturas del recuerdo: estudio introductorio. Trads. Johanna Córdoba y Tatjana Louis. Bogotá: Universidad de los Andes, 2012.

Fernández, Nona. La dimensión desconocida. Barcelona: Penguin Random House Grupo Editorial, 2017.

Friedman, Mary Lusky. "Tales from the Crypt: The Reemergence of Chile's Political Memory." Hispania 97.4 (2014): 612-22.

Franken Osorio, María Angélica. "Memorias e imaginarios de formación de los hijos en la narrativa chilena reciente." Revista chilena de literatura 96 (2017): 187 208.

Lauge Hansen, Hans. "El cronotopo del pasado presente. La relación entre ficcionalización literaria y lugares de reconocimiento en la novela española actual de memoria." La memoria novelada II: ficcionalización, documentalismo y lugares de memoria en la narrativa memorialista española. Eds. Juan Carlos Cruz Suárez y Diana González Martín. Bern: Peter Lang AG, 2013. ProQuest Ebook Central. Web. 16 abr. 2018.

Peller, Mariela. "Nona Fernández (2016) La dimensión desconocida.” Critical Reviews on Latin American Research 6.2 (2017): 64-6.

Poblete Alday, Patricia. "La crónica periodístico-literaria contemporánea en Chile." Estudios sobre el Mensaje Periodístico 20.2 (2014): 1165-76.

Rodríguez Marcos, Javier. “Nona Fernández: 'No quiero que el lector pase un buen rato" El País. 30 nov. 2017. Web. 18 jun. 2018.

Selicki Acevedo, Carolina. Página 12. 17 oct. 2014. Web. 17 jun. 2018.

Sepúlveda, Paulina. "Conversación Con Nona Fernández: ponerse en la piel del otro." Revista de Humanidades 29 (2014): 249-61. Redalyc.org. Web. 10 jun. 2018.

Torche, Pablo. "Una generación en busca de redención: a propósito de La dimensión desconocida, de Nona Fernández.” El Mostrador. 2 nov. 2017. Web. 19 jun. 2018.

Tschilschke, Christian von y Dagmar Schmelzer. "Docuficción: un fenómeno limítrofe se aproxima al centro." Docuficción. Enlaces entre ficción y no-ficción en la cultura española actual. Eds. Christian von Tschilschke y Dagmar Schmelzer. Madrid/Frankfurt: Iberoamericana/Vervuert, 2010. 
Willem, Bieke. "Desarraigo y nostalgia. El motivo de la vuelta a casa en tres novelas chilenas recientes." Iberoamericana 13.51 (2013): 139-57.

Yanes Mesa, Rafael. "La crónica, un género del periodismo literario equidistante entre la información y la interpretación” Espéculo. Revista de estudios literarios 11.32 (2006): s.p. 